\title{
LEADER DISTANCE: A REVIEW AND A PROPOSED THEORY
}

\author{
John Antonakis ${ }^{1}$ \\ Department of Psychology \\ Yale University
}

Leanne Atwater

School of Management

Arizona State University West

Forthcoming_-The Leadership Quarterly Annual Review

Submitted-August 2002

${ }^{1}$ Corresponding author, now affiliated with:

University of Lausanne

Faculty of Economics and Business Administration

(Ecoles des Hautes Etudes Commerciales-HEC)

BFSH-1

Lausanne, $\mathrm{CH}-1015$

Switzerland

Tel: ++41 (0)21 692-3300

e-mail: john.antonakis@ hec.unil.ch

Authors' note: We would like to thank Jerry Hunt, LQ Senior Editor, for his helpful comments and encouragement. We are also grateful for the feedback of the LQ 2002 Symposium Distinguished Scholar panel, participating LQ Editors, and attendees. 


\begin{abstract}
The concept of leader distance has been subsumed in a number of leadership theories; however, with few exceptions, leadership scholars have not expressly defined nor discussed leader distance, how distance is implicated in the legitimization of a leader, and how distance affects leader outcomes. We review available literature and demonstrate that integral to untangling the dynamics of the leadership influencing process is an understanding of leaderfollower distance. We present distance in terms of three independent dimensions: leader-follower physical distance, perceived social distance, and perceived task interaction frequency. We discuss possible antecedents of leader-follower distance, including organizational and task characteristics, national culture, and leader/follower implicit motives. Finally, we use configural theory to present eight typologies (i.e., coexistence of a cluster or constellation of independent factors serving as a unit of analysis) of leader distance and propose an integrated cross-level model of leader distance, linking the distance typologies to leader outcomes at the individual and group levels of analysis.
\end{abstract}

\title{
INTRODUCTION
}

The embers of "leadership at a distance"—as initially proposed by Bogardus (1927)— smoldered for half a century. They were briefly fanned by Katz and Kahn (1978), who cursorily referred to the leadership-at-a-distance phenomenon. Others (e.g., Napier \& Ferris, 1993; Shamir, 1995; Waldman \& Yammarino, 1999; Yammarino, 1994) have rekindled the idea of leadership at a distance. In its various forms, leader distance has been considered as (a) a sine qua non of the emergence of charismatic leadership (Katz \& Khan, 1978); (b) a moderator of the type of charismatic leadership that might emerge (Shamir, 1995; Yagil, 1998); and (c) a 
neutralizer of leadership that reduces the effect that leader behaviors have on others (Howell, Bowen, Dorfman, Kerr, \& Podsakoff, 1997; Kerr \& Jermier, 1978).

Napier and Ferris (1993), began their integrative review on distance and supervisorylevel leadership in organizations as follows: "Understanding the role of interpersonal distance in organizations is fundamental to our comprehension of work place dynamics, yet no theory currently exists that integrates the various types of distance in organizations" (p. 321). A similar comment was echoed by Yammarino (1994) who examined indirect leadership. Almost a decade has passed since these two studies were conducted; however, the literature on leadership at a distance in the organizational domain has yet to generate much empirical work, let alone define and bound the phenomenon of "leader distance."

Why do we need to study leadership at a distance? Although our current understanding of leadership is quite broad, we still do not understand the fundamental processes undergirding the influencing effect of leadership. For example, Yukl (1999) noted that our understanding of certain leadership theories, for example the Full-Range Leadership Theory (FRLT, i.e., transformational, transactional, and laissez-faire leadership) are limited in that the focus is generally on the dyadic level of analysis (i.e., direct leadership), instead of also group and organizational levels of analysis (i.e., indirect leadership). Hunt (1991), Shamir (1995), and Yammarino (1994) proposed that most theories of organizational leadership focus on supervisory-level leaders, and their effects on immediate followers.

Political scientists have, of course, long viewed the impact of leaders on far-removed followers (e.g., Burns, 1978; Gardner, 1990; Willner, 1984). Paradoxically, political scientists typically examined what could be termed "distal leaders;" however, leadership theorists, with few exceptions (e.g., Sashkin, 1988; Waldman \& Yammarino, 1999) have typically applied 
political science theories to explain the effects of what could be termed "proximal leaders" on followers.

The dynamics of the influencing process differ depending on how "close" or "distant" followers are from their leader. In other words, the types of leader behaviors that can affect followers and how those behaviors are evaluated by followers depend on how "close" or "distant" followers are from leaders. Briefly, we define leader distance as the configual effect (i.e., the coexistance of a cluster of independent factors-discussed later) of leader-follower physical distance, perceived social distance, and perceived interaction frequency. Thus, leaders can appear to be very distant to followers if leaders (a) are physically distant from followers, (b) maximize their status and power differentials by virtue of their elevated social position, and (c) maintain infrequent contact with followers. These three dimensions could, however, make leaders appear very close. We thus set out to answer the following questions in our article: Can both "distant" and "close" leaders influence followers? Can followers identify with and trust both types of leaders? What causes distance between leaders and followers? Is distance beneficial or detrimental to leader outcomes? Can we explain the linkages of "close" and “distant” leadership to individual and group level outcomes?

As we argue here, leader effectiveness is contingent on matching the degree of closeness that followers expect of the leader in various contexts (e.g., Roberts \& Bradley, 1988). Thus, a crucial component of the leadership phenomenon (i.e., how leaders are perceived, whether followers accept leaders, and the level of analysis at which leader outcomes are evident) can be partly explained by the distance that exists between leaders and their followers.

Furthermore, we argue that the construct of leader distance has abounded but has been implicitly subsumed in other leader constructs. Theoretical frameworks to guide research, 
however, are sparse. Conducting a review under such conditions was therefore especially challenging. As well as we can determine, after Napier and Ferris's (1993) review, our review is the second one dealing explicitly with distance and organizational leadership. Therefore, apart from reviewing the available literature we felt compelled to also define precisely what "leadership at a distance" is and the factors that comprise it. We also felt it necessary to integrate the disjointed findings and attempted to present a leader distance model (see Figure 1) and testable propositions that we hope will guide future research. Indeed, as noted by Napier and Ferris, "distance between supervisor and subordinate has been studied implicitly by a variety of researchers, leading to a myriad of findings with limited theoretical support, confusing and diverse operationalizations of constructs, and few if any comprehensive conclusions" (p. 325).

\section{LEADERSHIP AS AN INFLUENCING PROCESS}

Leadership is an influencing process that results from follower perceptions of leader behavior and follower attributions of the leader dispositional characteristics, behaviors, and performance (see Bass, 1990; Conger \& Kanugo, 1998; House, 1977; Shamir, 1995; Waldman \& Yammarino, 1999). One of the most popular theories of leadership is Bass and Avolio's (Bass, 1985; Bass \& Avolio, 1994; 1997) transformational, transactional, and laissez-faire leadership theory or Full-Range Leadership Theory (FRLT), which has played a salient role in shifting the current paradigms of leadership towards neocharismatic and transformational leadership (Conger, 1999; Hunt, 1999; Yukl, 1999). As such, we will use the FRLT as an example concerning what behaviors leaders enact and how leader distance moderates the types of fullrange leader behaviors that are visible and salient to followers.

Bass and Avolio argued that previous paradigms of leadership typically focused on the fulfillment of transactional obligations, and the types of leader behaviors associated with goal 
establishment, and the rewarding or sanctioning of follower behavior contingent on goal achievement. This type of leadership was referred to as transactional leadership, which was limited to inducing basic changes in followers. Following the work of Burn's (1978), Bass and Avolio theorized that a more potent form of leadership was needed to elevate the influencing process to a higher level. By virtue of their visionary, inspirational, and charismatic behaviors, Bass and Avolio argued that transformational leaders focus on elevating followers' higher-order needs to achieve extraordinary and worthy feats, and to make followers aware of and believe in superordinate values and goals.

In its current form, Bass and Avolio (1997) argued that transactional leadership comprises (a) management-by-exception passive (i.e., a passive-corrective transaction); (b) management-by-exception active (i.e., an active-corrective transaction); and (c) contingent reward (i.e., a constructive transaction). Transformational leadership, which is seen as the most active and effective leader style, comprises (a) attributed idealized influence (i.e., attributed charisma); (b) behavioral idealized influence (i.e., behavioral charisma); (c) inspirational motivation (i.e., raising follower self-efficacy beliefs); (d) intellectual stimulation (i.e., encouragement of creative thinking and challenging the status quo); and (e) individualized consideration (i.e., individualized follower development). The FRLT is completed by laissezfaire leadership, which entails the absence of leadership and transactions. The FRLT is measured by the Multifactor Leadership Questionnaire Form 5X (Bass \& Avolio, 1995).

Although the FRLT may be the flag bearer of the neocharismatic leadership movement, it omits important leader behaviors, which Antonakis and House (in press) referred to as instrumental leadership. Instrumental leadership theoretically accounts for leader behaviors that are independent of value-based or transactional behavior that are (a) strategic in nature (i.e., 
strategy formulation and implementation), impacting the organizational level of analysis, and (b) focused on follower work facilitation (i.e., path-goal facilitation, and outcome monitoring). Thus, our examples will be based on the extended Antonakis and House FRLT.

An important factor associated with how leadership as process impacts followers is leader hierarchical level, which, as we establish later, is associated with leader distance. High-level leaders display qualitatively different behaviors from low-level leaders (e.g., Antonakis \& House, 2002; Hunt, 1991; Sashkin, 1988; Waldman \& Yammarino, 1999; Westley \& Mintzberg, 1988; Zaccaro, 2002). Thus, hierarchical level, as a contextual factor, should be considered as a boundary condition of leadership models. For example, Antonakis (2001) found support for the validity of the nine-factors of the FRLT; however, he demonstrated that the validity of the model depended on using data from contextually-similar conditions, one of which included leader hierarchical level. In a meta-analysis, Lowe, Kroeck, and Sivasubramaniam, (1996) established that the mean of the leadership factors were moderated by leader level. The implication of these findings is that leaders will enact different behaviors depending on the context in which those behaviors occur. Therefore, because the FRLT may not operate in the same manner across various hierarchical levels and within different degrees of leader-follower distance, it is important that we make explicit how distance may moderate the types of leader behaviors that may emerge or are visible.

\section{Follower identification and trust}

Before reviewing the dimensions of leader distance, we briefly discuss why followers identify with and trust charismatic/transformational leaders, and how the identification process may occur differently depending on leader distance. As we will argue, the legitimacy of a leader is moderated by leader distance. Furthermore, how followers come to identify with their leader 
or the collective is a function of leader distance. Because identification with the leader is a result of the leader's charisma (Bass, 1985; House, 1977), as a prelude to our detailed discussion on the dimensions of leader distance, first we briefly explore how leader charisma emerges and how charisma may be related to leader distance. For simplicity, when we refer to charisma we are referring to a leader's idealized influence as well as the leader's inspirational motivation, individualized consideration and intellectual stimulation. As argued by Antonakis and House (in press), current explications of transformational leadership are similar to the descriptions of charismatic and visionary leadership, and — apart from instrumental leadership—most of the dimensions of charismatic/visionary leadership are theoretically captured by the FRLT.

According to House (1977), a charismatic leader becomes a symbol of identification for followers, and commands loyalty, trust and devotion from followers resulting from the leader's transcendent vision and the confidence the leader instills in followers that the vision is achievable. Others have argued that the charismatic leader's vision of a highly attractive future that challenges and breaks with the past creates follower identification with the leader (Bass, 1985; Conger \& Kanugo, 1998).

In their self-concept based theory of charismatic leadership, Shamir, House, and Arthur (1993) argued that individuals are motivated to self-express, to enhance their self-worth, selfesteem and self-efficacy, and to establish an identity of who they are. If these self-concepts can be expressed in a charismatic leader or in a collective, individuals can come to identify with the charismatic leader and with the collective. That is, followers' self-concepts are affected and implicated by the charismatic leader-especially when the leader represents what followers and the group consider to be salient values_-values that implicate the followers' social identity. According to Ashforth and Mael (1989), identification with the collective is referred to as social 
identification or "the perception of oneness with or belongingness to some human aggregate" (p. 21). They noted further that individuals will "choose activities congruent with salient aspects of their identities, and they support the institutions embodying those identities" (p. 25). Thus, Shamir et al. noted that followers become self-motivated to perform in conditions where the leader implicates their self-concepts and social identity.

Conger and Kanugo (1998) noted that charisma "is both a relational and attributional phenomenon" (p. 38). The leader's charisma is thus legitimized by virtue of his or her actual behaviors and whether the behaviors are observable to followers (implying that leaders are "close" to followers; see Shamir, 1995), or attributions that followers make of the leader (implying that leaders are "distant" from followers") resulting from (a) the leader's impression management techniques (see Gardner \& Avolio, 1998; Shamir, 1995; Waldman \& Yammarino, 1999); (b) a social contagion effect, whereby followers' perceptions and attributions of the leader spread to others (see Meindl, 1990); (c) from the leader's social network, that is, "the social systems in which [followers] are embedded. ... and the thinking and behavior of other social actors to whom they are exposed" (see Pastor, Meindl \& Mayo, 2002, p. 410); (d) implicit leadership theories that followers have of leaders (see Eden \& Leviatan, 1975); or (e) followers may also attribute charisma to high-level (and generally "distant") leaders based on attributions followers make regarding the performance of the leaders' organizations (see Shamir, 1995; Waldman \& Yammarino, 1999).

However, it appears that these attributional effects depend on how much information followers have of leaders. For instance, attributional effects would be more prevalent for "distant" than for "close" charismatic leaders, because followers of distant leaders are more prone to leader image-building efforts and have less information on the leader (see Shamir, 1995; 
Shamir \& Howell, 1999). Because individuals may not have enough information on a leader to make an accurate assessment of the leader's behavior and performance, they may make assumptions and attributions to rationalize and comprehend organizational outcomes (see Meindl \& Ehrlich, 1987; Yukl, 1998). It follows therefore, that the knowledge followers have of the leader's performance and how the leader's performance affects the organization is critical to whether they (a) directly evaluate the leader's performance or (b) whether they attribute organizational success to the leader's performance and image-building efforts. Further discussion on attributional and relational charisma is presented later in our coverage of social distance.

Proposition 1: Followers will identify with leaders as a result of the leaders' relational or attributional charisma.

Proposition 2a: Followers who interact directly with their leaders are more able to directly evaluate the leader's performance than followers who interact indirectly with their leaders.

Proposition 2b: Followers who can directly evaluate their leader's performance will be more prone to the effects of relational leader charisma than to attributional charisma.

Proposition 3a: Followers who interact indirectly with their leaders will rely more on attributions of the leaders' performance than will followers who interact directly with their leaders.

Proposition 3b: Followers who cannot directly evaluate their leader's performance will be more prone to the effects of attributional leader charisma than to relational leader charisma.

Note: "followers" in the above propositions can refer to immediate (e.g., subordinates or subordinate leaders) or nonimmediate followers (i.e., indirect followers) of a leader. 
Apart from identification with the leader, follower trust in the leader has also been viewed as an outcome of charisma (Bass, 1985; House, 1977). As we argue later, trust may take on two forms (i.e., "close" and "distant" trust) as a function of leader distance. Thus, it is important here that we describe how trust develops, and its multidimensional nature, so that we can later link trust to leader distance.

Mayer, Davis, and Schoorman (1995) suggested that the propensity to trust an individual is a function of the trustee's (a) ability (i.e., expertise), (b) benevolence (i.e., altruism), and (c) integrity (i.e., consistency). Ability is related to instrumental leader behavior, because the latter is predicated on the leader's domain-relevant expertise and impacts follower and organizational performance (see Antonakis \& House, 2002). Benevolence is related to a leader's socialized charisma (see Antonakis \& House, in press) that is, the degree of overlap between leader and follower values such that that leader is acting congruent to the values of the collective, challenging the status quo for the better (i.e., using intellectual stimulation) demonstrating conviction that collective goals are achievable (i.e., using inspirational motivation), and finally empowering followers (i.e., using individualized consideration). Integrity is related to the leaders' honesty and reliability and whether they fulfill their transactional obligations (see Shamir, 1995).

Similar to our discussions above about the implications of distance to leader charisma, it becomes apparent that the dimensions of trust may not arise in the same manner because of leader distance, as we also discuss later. Briefly, a leader's ability and integrity is evident to followers if they have direct information on the leader's performance and behavior and are "close" to the leader; however, a leader's ability and integrity are not easily determined if followers do not have direct information on the leader and are "distant" from the leader. 
Therefore, the ways in which a leader is legitimized and trusted appears to be a function of leader distance.

\section{“CLOSE” AND “DISTANT” LEADERSHIP}

Distance, as it refers to leadership, has been generally discussed in terms of social or psychosocial distance (e.g., Bass, 1990; Bogardus, 1927; Shamir, 1995; Waldman \& Yammarino, 1999), physical distance (Kerr \& Jermier, 1978), in terms of the maintenance of frequent and direct contact of leader with followers (Hunt, 1991; Yagil, 1998; Yammarino, 1994), and in terms of hierarchical or cross-functional leadership (Bass \& Avolio, 1993; Hunt, 1991; Yammarino, 1994). In this section, we discuss literature that has explicitly considered the effects of distance on leadership. We also include theories of leadership in which distance was implicitly assumed but not expressly discussed. In reviewing the literature, we concluded that distance can be manifested in three independent dimensions, that is, leader-follower physical distance, perceived social distance, and perceived leader-follower interaction frequency. The degree to which these three dimensions are manifested in the leader's behavior will affect the degree to which followers perceive the leader as "close" or "distant."

\section{Distance in leadership theories}

Many leadership scholars have based their theories of leadership on an assumption that some sort of distance, or lack thereof, is prevalent in leader-follower relationships. We review a few examples below.

In the Ohio State University studies, Halpin and Winer's (1957) definition of leader consideration implied that a leader was intimate and close to followers. Other conceptualizations inferring closeness include Blake and Mouton's (1964, p. 57) “country club” managerial style 
(i.e., high concern-for-people leaders), describing leaders as being friendly, informal, sociable, promoting togetherness, and reducing status differentials with followers. Also, the scale of "individualized consideration" in the FRLT refers to leader behaviors that provide individualized and personalized attention to followers implying leader-follower closeness and intimacy (Bass, 1985, 1998).

Some conceptualizations imply distance. Fiedler's (1967) Least Preferred Coworker, based on the Assumed Similarity between Opposites scale, referred in part, to the preferred psychological distance a leader wished to maintain from followers. White and Lippitt (1968) described authoritarian leaders as being aloof (i.e., socially distant) from their group of followers, whereas democratic leaders were more egalitarian and unconcerned by status differentials. House (1977) argued that charismatic leaders can either be, or can create the impressions to be, confident, dominant, and successful, thus implying that leaders create these impressions because followers cannot directly assess the leaders' behaviors and attitudes (i.e., the leader is "distant" from the followers).

Still other conceptualizations suggest that leaders may be either close or distant. LMX theory describes the quality of dyadic relations (i.e., leader-follower) that characterize whether the relationship is based primarily on the mutual fulfillment of contractual obligations (i.e., the "out group") or whether the relation will be based on trust, respect, and positive social exchange (i.e., the "in group") (Uhl-Bien, Graen, \& Scandura, 2000). Kerr and Jermier (1978) noted that leadership may be unnecessary and that the degree of closeness of leader supervision will depend on various leader "substitutes," which include among others, follower abilities and various organizational systems and processes. 
Although some scholars have specifically examined the implication of distance on leadership, they generally have not explicitly defined what they meant by "distance." The only explicit definition of leader distance has been offered by Napier and Ferris (1993), who referred to the distance between a leader and a follower as dyadic distance, "a multidimensional construct that describes the psychological, structural, and functional separation, disparity, or discord between a supervisor and a subordinate" (p. 326). They speculated that functional distance mediates the relations of psychological and structural distance in determining subordinate performance and satisfaction. The three dimensions of distance that Napier and Ferris identified included:

1. Psychological distance - this refers to the "psychological effects of actual and perceived ... differences between the supervisor and subordinate" (p. 328-329). These differences or similarities include (a) demographic distance, which refers to age, race, and gender differences (similar to how social distance has been defined, as discussed below); (b) power distance, which refers to follower acceptance of power differentials between the follower and the leader (also similar to social distance); (c) perceived similarity, which refers to "the degree to which an individual believes that s(he) is similar to a target individual" (p. 331), (also appears similar to social distance); and (d) values similarity, which refers to similarity of "beliefs, values, or attitudes" (p. 332) between followers and their leader (appears similar to our description of follower identification with the leader).

2. Structural distance - this refers to "aspects of distance brought about by physical structure [e.g., physical distance], as well as organizational structure [e.g., span of management control and management centralization] and supervision structure [e.g., frequency of leader-follower interaction]" (Napier \& Ferris, 1993; p. 333). It is discussed in terms of 
propinquity (i.e., proximity). They stated further, "The conceptual link which binds [the above three] variables is that they all are associated with the amount of interaction in the dyad which is allowed or encouraged" (p. 333).

3. Functional distance-refers to the "degree of closeness and quality of the functional working relationship between the supervisor and the subordinate; in essence, whether the subordinate is a member of the in-group or the out-group" (Napier \& Ferris, 1993, p. 337), suggesting leader-follower intimacy. They argued that functional distance is comprised of affect, perceptual congruence (i.e., mutual understanding), and latitude (i.e., the degree of follower empowerment). Here, Napier and Ferris draw heavily upon LMX theory.

There are a number of ways we expand Napier and Ferris's (1993) model, which seems to be more normative than descriptive. First, Napier and Ferris suggest that functional distance is a negative predictor of subordinate outcomes, for example, "Subordinates who feel they have access to their supervisors, and who actually interact on a more frequent basis, are hypothesized to develop a better, closer working relationship" (p. 344). They stated further "less functional distance is proposed to lead to higher performance evaluations, higher subordinate satisfaction, and lower subordinate withdrawal" (p. 344). We believe this proposition is premature for the below reasons.

Their explication of distance relates in toto to leader-follower intimacy, which is not a necessary condition for the emergence of successful leadership. The type of charisma ascribed to a leader will vary depending on the degree of social distance (i.e., intimacy) prevalent in the leader-follower relationship (Shamir, 1995; Yagil, 1998). Intimacy is not a necessary condition for the emergence of successful charismatic leadership (Shamir, 1995). The closeness of leaderfollower interaction depends on a variety of factors, for example, follower skills (House, 1971) 
and leader substitutes (Kerr \& Jermier, 1978). Additionally, as discussed previously, affect for, identification with, and trust in the leader is predicated on numerous factors, and does not necessitate that a leader is intimate with his or her followers.

Second, Napier and Ferris (1993) argued that functional distance mediates the effect of psychological and structural distance in determining subordinate performance and satisfaction. Again, in focusing on supervisor-level leadership and only on a single unit of analysis, the dyadic follower-leader relation, they have not considered the effects of high-level leaders on groups and collectives.

Third, in contrast to Napier and Ferris (1993) we suggest that identification and social distance need to be considered as independent of each other. Identification with the leader is possible when leader-follower social distance is large or small.

Finally, Napier and Ferris (1993) stated that factors that moderate the emergence of distance should be investigated, including "the nature of the task, the use of impression management behaviors, instrumental or expressive orientations and other personality characteristics, size or industry type and other organizational constraints, and location or culture of the organization" (p. 349). Although their commentary is very insightful, those recommendations were not included in the formulation of their normative model. Based in part on their work, we hope to present a more general model and distinct definitions of the multidimensional nature of distance.

In the following sections we present the three distance dimensions and relevant literature to support their conceptualization. 


\section{Perceived social or psychological distance}

Social distance, which we generally equate to psychological distance (Napier \& Ferris, 1993) or psychosocial distance (Bass, 1990), was first described by Park (1924) to refer to degree of "understanding and intimacy which characterize personal and social relations" (p. 339). Social distance can include differentials in status depending upon the context in which they are observed (Bogardus, 1928; Park, 1924), and the degree to which individuals are personally acquainted with one another (Frank, 1974). We thus define social distance in the leadership domain as perceived differences in status, rank, authority, social standing, and power, which affect the degree of intimacy and social contact that develop between followers and their leader.

Bogardus (1927) first proposed that leadership entails a degree of social distance between a leader and followers, which he referred to as vertical social distance. He speculated that social distance is created because the leader is accorded recognition by followers for outstanding feats in a particular domain. By definition, therefore, leadership is accompanied by social distance. Bogardus was the first to note, "To the extent that leadership rests on sheer prestige, it is easily punctured by intimacy" (p. 177). In other words, leaders' influence and the respect they command diminish when the social distance between them and their followers is reduced, because followers can more easily see a leader's weaknesses.

As discussed below, however, in the presentation of Shamir's (1995) work, leader charisma can be evident both in socially distant and close situations. Shamir noted, "For many years, it was assumed that the concept of charisma was inapplicable to lower-level leaders or close leadership situations" (p. 19) (see Etzioni, 1961; Katz \& Kahn, 1978). For example, Katz and Kahn noted explicitly "subordinates cannot build an aura of magic about [immediate leaders]. Day-to-day intimacy destroys illusion. But the [top-level] leader . . . is sufficiently distant from the membership to make a simplified and magical image possible" (p. 546). 
Bogardus (1927) noted that even in socially close situations it is possible for leaders to maintain their influence if they are recognized for their unique expertise in a particular domain, or if their followers have a high degree of affection for them. We interpret affection in this context to refer to the identification of the followers with their leader, following our discussions about the charismatic effect. Indeed, Bogardus noted, "Great affection for a [leader] will cause [an individual] to remain a faithful follower despite gross weaknesses in the life and character of the leader" (p. 177). As noted by Bass (1990), "Social distance between leaders and followers is not essential for the maintenance of the charismatic relationship" (p. 199). Rather, charisma is a function of ideal-based behavior and appeals to transcendent goals that arouse follower motives to pursue these goals as symbolized by the leader (see Bass, 1985; House, 1977).

Yagil (1998) stated that followers view leader social [and physical] proximity as being beneficial, because proximity allows the leader to "deliver sensitive and individually tailored confidence-building communications [i.e., individualized consideration and inspirational motivation], which are probably more effective than messages addressed to the group as a whole" (p. 172). Yagil argued further that, apart from being more approachable, a leader that is physically close to followers has the opportunity to role model effective behaviors. Furthermore, following Aronson, Willerman, and Floyd (1966), Yagil argued that proximity may make the leader appear more human and fallible, thus undergirding the identification effect. In fact, as demonstrated by Aronson et al., individuals to whom status was ascribed were viewed more favorably when committing a clumsy blunder of sorts as compared to individuals who are ascribed less status. However, Yagil also demonstrated that socially [and physically] distant leaders are still attributed charisma and have group-level effects as opposed to individual-level effects. 
In his germinal article that related social distance to leadership Shamir (1995) outlined important distinctions between socially close and socially distant charismatic leaders, but stressed that charisma may emerge in both case. Similarly, Yammarino (1994) argued that transformational leadership has a direct as well as an indirect effect on followers depending on leader hierarchy. In other words, transformational leadership or indeed other styles of leadership can work effectively even though the leader is not in direct contact with followers.

According to Shamir (1995), socially-distant leaders will more readily invoke attributions of exceptional qualities because of organizational performance cues, image-building techniques, visionary behaviors, use of rhetoric, and articulation of ideology, which can create the charismatic effect and an idealized leader (we referred to this type of charisma as attributional charisma). Socially-close leaders will mainly be ascribed charisma based on followers' observations of the leader's performance, and the personal examples the leaders set (we referred to this type of charisma as relational charisma).

Shamir (1995) also noted that the way trust develops in leaders is moderated by distance; socially-close leaders can engage in transactional behavior, which, if mutually beneficial, serves to build trust and can undergird the charismatic effect (see Waldman \& Yammarino, 1999). This effect is prevalent because through direct interactions "the leader's honesty, reliability, and trustworthiness can be directly manifested by the leader and assessed by close followers" (Shamir, p. 26). Furthermore, socially-close leaders can empathize with followers and demonstrate individualized consideration-as opposed to socially-distant leaders who do not have opportunities to practice such leader behaviors_-which may further build trust in the leader. We refer to this type of trust as "close" trust. Distant leaders may develop trust as a function of attributions regarding the leader's ethical, moral, and altruistic orientations. Because distant 
leaders are more idealized, Shamir noted they are trusted unconditionally (i.e., blindly). We refer to this type of trust as "distant" trust.

As discussed, socially-close or distant leadership does not preclude the identification of followers with leaders. The two types of leadership operate differently, but both types of leaders can be ascribed charisma. The distinction that Shamir (1995) made between socially close and distant leaders is also important in terms of determining the level at which leader outcomes are evident. Briefly, it appears that the outcomes of socially-distant leaders would be theoretically evident is at the group level of analysis, because the leaders would tend to behave homogenously with followers; however, the outcomes of socially-close leaders would theoretically be evident at the individual level of analysis, because the leaders would treat followers individually. We examine this issue in detail later in our discussion regarding levels of analysis.

Although Shamir (1995) did not precisely define what he meant by social distance, implicit in his explications is that socially-distant leadership is prevalent in high-level leaders that are physically distant, who have infrequent and indirect contact with their followers, and whose followers cannot readily observe the day-to-day functioning of their leader (i.e., the leaders are inaccessible to followers). As will be evident later, this assumption may not be tenable because social distance can emerge regardless of leader level, leader proximity, and leader-follower contact. It thus becomes evident that Shamir's propositions do not include a provision for physically close leaders who maintain a high degree of social distance, but also frequent and direct contact with followers. Thus, perceived frequency of leader-follower interaction and physical distance must be included in a complete definition of distance. 


\section{Physical distance}

We simply define physical distance as how far or how close followers are located from their leader. It is important that we differentiate physical distance from social distance, because some authors have suggested that the effects of these two constructs may operate in a similar manner (e.g., Howell \& Hall-Merenda, 1999; Howell, Neufeld, \& Avolio, 1998, 2002), and that social distance may imply that followers are physically distant from their leader (e.g. Shamir, 1995). Social distance and physical distance are distinct. For example, it is highly feasible for a leader to be proximally located, but to be socially distant. Furthermore, it is equally possible for a leader to be distally located, but to be socially close. Indeed, as acknowledged by Howell et al. (2002), theoretically, leadership could function differently in terms of the joint effects of social and physical distance.

Kerr and Jermier (1978) noted that physical distance creates "circumstances in which effective leadership may be impossible" (p. 396). They noted further that physical distance neutralizes leadership behaviors, that is, "make it effectively impossible for relationship and/or task-oriented leadership to make a difference" (p. 395). Howell et al. (1997) noted that distance renders "many recommended leadership practices ... nearly impossible to perform" (p. 389). Although in principle we agree that physical distance creates challenges for leaders and in certain situations may be negatively associated with leader outcomes, as we argue later, physical distance may indeed be a necessary requisite for effective leadership. We also believe that because of advances in technology, physical distance may not have the "neutralizing effect" that it did several decades ago when Kerr and Jermier proposed their theory.

Napier and Ferris (1993) argued that less functional distance should be associated with higher performance and follower satisfaction, and less subordinate withdrawal, which suggests 
that physical distance between followers and their leader should be minimized. Again, although in principle we agree with their position as it applies to certain situations, their proposition is limited given that Napier and Ferris dealt mostly with supervisory-level leadership. This criticism may also be directed to the majority of the findings below.

Regarding the effects of distance, Bass (1990) noted that distance has a negative effect on the quality of the exchange, and reduces the leader's influence. This effect may be prevalent because of the reduced richness of information transmission (see Daft \& Lengel, 1984). Similarly Bass (1998) proposed that physical distance may neutralize the effects of leaders as a result of reduced social interaction. It also becomes difficult for leaders to monitor outcomes, because leaders cannot directly observe follower behavior (Yagil, 1998). Consequently, administering timely rewards and punishments becomes challenging in these types of conditions. Podsakoff, Todor, Grover, and Huber (1984) demonstrated that use of noncontingent punishment increased along with an increase in physical distance. Podsakoff et al. further demonstrated that the use of contingent rewards was negatively related to physical distance. As argued by Howell and Hall-Merenda (1999), noncontingent management-by-exception may have more deleterious effects than does contingent management-by-exception. Furthermore, it may also be possible that lack of leader interaction may be perceived as the type of inactivity displayed by laissez-faire leaders, which as noted by Bass (1998) are the least effective leaders portrayed in the FRLT.

Physical distance may also make it difficult for a leader to monitor and rate follower performance. For example, Judge and Ferris (1993) demonstrated that the more opportunities leaders had to observe follower performance the higher they rated follower performance. Physical distance in the leader-follower relationship has been found to be positively related to perceptions of group role conflict and negatively related to group altruism (Podsakoff, 
MacKenzie \& Bommer, 1996a, 1996b). In their meta-analysis, Podsakoff et al. (1996b) also demonstrated that physical distance negatively impacted follower performance, conscientiousness, and civic virtue. Similarly, Burrows, Munday, Tunnell and Seay (1996) found that physically-distant leaders negatively impacted follower satisfaction. However, in contrast to the above findings, Howell et al. (1998) found that distance strengthened the relation between charismatic leadership (i.e., idealized influence) and organizational performance, and stated, "physical proximity between charismatic leaders and followers appears to reduce the potency of the leader's visionary message" (p. 29). Because Howell et al. used an older version of the Multifactor Leadership Questionnaire, which did not draw a fine line between behavioral and attributional charisma, it is difficult to determine the role of the idealized influence components in these results.

Howell and Hall-Merenda (1999), argued that a key contextual moderator of the quality of leader follower relationships is physical distance. Howell and Hall-Merenda gathered measures of LMX, transformational leadership, contingent-reward leadership, management-byexception active and management-by-exception passive, and rated performance of followers, and found that physical distance moderated the effectiveness of leadership behaviors. Specifically, transformational leadership was significantly more related to performance in close than in distant conditions (this finding was replicated by Howell et al., 2002), whereas contingent reward leadership was significantly more related to follower performance in distant than in close conditions. They also found that active management-by-exception was significantly related to performance in close but not distant leader conditions, and that passive management-byexception was more negatively related to performance in close rather than in distant conditions. Interestingly, the relation between LMX and follower performance was not moderated by 
physical distance, which contradicts previous findings and theorizing that physical distance is detrimental to leader-follower relations and leader outcomes.

The impact of transformational leadership in the above study cannot be well understood because the transformational leadership items were aggregated across scales to form one overall measure of transformational leadership. As discussed previously, it is theoretically possible that the type of charisma ascribed to leaders and the types of full-range behaviors leaders can use (e.g., individualized consideration) are moderated by leader distance. Furthermore, it may be possible that the distant leaders in their sample were not rated highly in charisma, and close leaders were not rated highly on individualized consideration. The scale aggregations thus limit the interpretations we can make from these results.

In all, it appears that physical distance acts as a negative moderator on leadership outcomes. However, empirical results demonstrate that LMX is related to leader outcomes regardless of physical distance suggesting that the neutralizing effect of distance can be overcome. Furthermore, charismatic leadership (i.e., idealized influence in general) appears to have more of an impact when leader-follower physical distance is large.

\section{Perceived frequency of leader-follower interaction}

Following Napier and Ferris (1993), the third dimension of distance we propose is perceived leader-follower interaction frequency. This dimension is defined as the perceived degree to which leaders interact with their followers. Although this dimension does not connote "distance" of sorts, it directly impacts how "close" a leader may seem to a follower. In other words, followers who have frequent interactions with their leader have a "closer" relationship with their leader than followers who have infrequent interactions with their leader. This dimension is independent of social and physical distance. Although physical distance may make 
it more likely that leader-follower contact is infrequent, distance does not cause infrequent leader-follower contact. For example, it is theoretically possible that a proximally located leader maintains infrequent contact with followers. Furthermore, with the aid of technology, it is also possible that a distally located leader maintains frequent contact with followers.

A distinction that must also be made here too is that frequency of interaction does not necessarily imply good leader-member exchanges, as suggested by LMX theory. Although we would intuitively expect a relation, as suggested by House (1971), House and Mitchell (1974), House and Dessler (1994), and Kerr and Jermier (1978), the optimal degree of leader-follower interaction and follower satisfaction in a leader is contingent on situational variables. In certain situations (e.g., task ambiguity) followers would require frequent task or socio-emotional interaction with their leader, whereas in other situations they may require less frequent interaction with their leader. Frequency of interaction, therefore, is related to the degree of direction and feedback followers will receive and seek. For instance, Ashford and Cummings (1985) noted that followers initiate feedback-seeking behaviors, especially when ambiguities regarding roles and tasks are presented in the working environment, or if followers are newly tenured and inexperienced.

Thus, frequency of interaction can operate independently of physical and social distance and contributes directly to follower perceptions of total leader distance. Higher frequency of interaction will be associated with leader closeness, whereas lower frequency of interaction will be associated with leader distance. Quality of interaction may not necessarily be related to quantity of interaction. Furthermore, the need for frequency of interaction will depend on contextual factors, as we discuss later. 
Proposition 4: Leader-follower physical distance, perceived social distance, and perceived interaction frequency are independent, measurable dimensions each describing an element of leader distance.

\section{Typologies of distant leadership}

Apart from Shamir and Ben-Ari (1999) who briefly discussed the implications of socially and physically distant leadership, we did not locate any studies that addressed the combined nature of leader distance as a function of social and physical distance. By combined nature, we mean "the multidimensional constellation of conceptually distinct characteristics [in our case the three distance dimensions] that commonly occur together" (Meyer, Tsui, \& Hinnings, 1993, p. 1175). That is, the three distance dimensions (i.e., leader-follower physical distance, perceived social distance, and perceived interaction frequency) are conceptually independent and, theoretically, can be found to occur concurrently in varying degrees.

According to Meyer et al. (1993), what can be termed as the "configurational approach" to studying organizational, group, and individual-level phenomena typically leads to clusters of configurations or typologies that can be conceptually (e.g., Smith \& Foti, 1998) or empirically derived (e.g., Jermier, Slocum, Fry, \& Gaines, 1991). The typology—in this case the "distance style" adopted by the leader-is useful as a unit of analysis because the variables of which it is comprised cannot be studied alone or additively (Meyer et al., 1993; Smith \& Foti, 1998). Smith and Foti argued that leaders should be classified based on patterns of variables and not simply by the variables in isolation of each other. Smith and Foti classified leaders on three dispositional variables (i.e., dominance, self-efficacy, and intelligence) and used a median split to derive eight "multivariable patterns." Similarly, based on the occurrence of either a high or low value of the three distance dimensions, we conceptually identified eight typologies of distant leadership. 
Thus, data on the distance dimensions could be gathered on leaders, who could then be categorized according to one of the eight typologies. The data of leaders in the respective typologies could then be linked to various intermediate or dependent outcomes.

Where possible, we provide examples below of leaders that that fit our eight labels of leader distance. We have also named the typologies for ease of reference. Our descriptions of the eight typologies of leader distance below are not normative; that is, a particular typology is not necessarily better than another. The success of the type of distant leadership employed by the leader will depend on situational moderators (discussed later). The total permissible (i.e., normative) distance in the leader-follower relation will depend on the context. For example, UhlBien et al. (2000) noted that conditions that characterize high leader-follower interdependence theoretically require "close" LMX relations, whereas low leader-follower interdependence could theoretically be accompanied by "distant" LMX relations.

Furthermore, it is possible that two individuals fit a particular typology, but that one leader is successful and the other is not. Some of the leaders that we present below were either authentic (e.g., F. D. Roosevelt) or inauthentic (e.g., Hitler). Also, it is possible that any of the major classes of leadership comprising the FRLT (i.e., transformational, instrumental, transactional, and laissez-faire leadership) can be used to describe the leadership styles of leaders within any of the eight typologies.

The eight typologies of distance include the following (note: $\mathrm{H}=$ high; $\mathrm{L}=$ low; $\mathrm{P}=$ physical distance, $\mathrm{S}=$ perceived social distance, and $\mathrm{F}=$ perceived leader-follower interaction frequency):

1. Proximal leadership ( $P=L, S=L, F=H)$. Kegan's (1987) portrayal of Alexander the Great is a good example of the proximal leader who commanded great respect and loyalty from his followers. Although Alexander was a hierarchically high leader, he led by example, 
maintained close contact with his soldiers, treated them as equals, led them personally into battle, and fought shoulder-to-shoulder with his soldiers, many of whom he knew personally. He made a point of personally communicating with his troops at critical times, for example, by repeating his battle speech so that all his troops could personally hear his intent.

2. "Hands-off" leadership ( $P=L, S=L, F=L)$. These leaders are physically and socially close but maintain infrequent contact with their followers. An example is the type leader that is accessible to followers and can speak intimately with followers, but does not interact frequently with followers as a result of "leader substitutes," that exist in the organization (e.g., Howell, Bowen, Dorfman, and Kerr (1990).

3. Virtually-close leadership $(P=H, S=L, F=H)$. This type of leader is what Avolio, Kahai, and Dodge (2001) referred to as an "e-leader." Although operating in a low technology epoch, Ulysses Grant fits our label of this type of leader. According to Kegan (1987), Grant maintained frequent contact with his subordinates and empathized with them. Grant, though, hated the site of blood and battle, was always distant from the front lines, and led from behind. As such, he made frequent use of technology—dispatch and telegraph—to keep in touch with his subordinates and to be informed of battle developments. Grant was modest and very courteous to subordinates and considered his subordinates as equals. According to Kegan, Grant "often ate more simply than his staff" (p. 204), and "his accustomed outfit was a private's coat, on which he pinned his general's stars" (p. 206).

4. Socially-distant leadership $(P=L, S=H, F=H)$. The Duke of Wellington is a good example of a socially distant leader. Kegan (1987) described Wellington as maintaining frequent contact with his soldiers, and commanding from close at hand. However, he was "icy, distant, loftily contemptuous, the voice of someone speaking across an unbridgeable gap set between him 
and the groundlings. ... Wellington really did not seem to love his soldiers, or perhaps even to know them" (p. 127). Wellington maintained a stiff upper lip, and was always well composed. He was "aloof and supervisory in bivouacs or on the line of march" (Kegan, 1987, p. 155).

5. Virtually-distant leadership $(P=H, S=H, F=H)$. These types of leaders, physically and socially distant, but with heavy reliance on technology, are able to maintain frequent contact with followers. As a description of the "digitized" military of the future, Shamir and Ben-Ari (1999) referred to this type of leadership as teleleadership, that "de-emphasizes the social and human elements ... and presents a very 'cold' prototype of a technical manager in place of a . . leader" (p. 17).

6. Avuncular leadership $(P=H, S=L, F=L)$. Although a high-level, physically-distant political figure, F. D. Roosevelt typified the avuncular leader; he championed the cause of the commoners, paid attention to them (e.g., through town meetings), emphasized social equality, used colloquial and folksy phrases, and appeared to be warm hearted (Willner, 1984). In other words, he created the impression of being socially close to common citizens even though he did not interact often with them.

7. Manor house leadership ( $P=L, S=H, F=L)$. An example of this type of leader is Waldman and Yammarino's (1999) description of a typical CEO, who, although he or she may be proximally located with followers, is socially distant from them and generally interacts with followers indirectly (and with subordinate leaders directly) ${ }^{1}$. These types of leaders do not, and cannot, know their followers intimately, nor do they share personal information about themselves with their followers.

8. Distal leadership $(P=H, S=H, F=L)$. Adolf Hitler is a good example of a distal leader. Kegan (1987) portrayed Hitler being physically and socially distant from his troops. Contact with 
his soldiers was infrequent and staged. He was disinvolved from them, and was aloof, and primarily interacted with his subordinate leaders.

The type of distance perceived by a follower will thus be a function of how the leadership style of the leader is perceived. For example, Hede and Wear (1996) demonstrated that the transformational or transactional leadership styles of high-level political leaders varied, depending on the vantage point from which the leader was observed (i.e., how close or distant the follower is from the leader). This suggests that (a), by virtue of their contextualized (i.e., tacit) knowledge, (i.e., implicit knowledge derived experientially—see Antonakis, Hedlund, Pretz, \& Sternberg, 2002) leaders can alternate from being distant to close, depending on situational requirements; (b) close and distant followers perceive the leader differently (as discussed previously); or (c), both (a) and (b). Thus, subordinate leaders of a CEO may see the CEO as a proximal leader, because the CEO may be physically and socially close to them, and maintain a high degree of leader-follower interaction. However, low-level, indirect followers may see the CEO as a manor house or distal leader, depending on the physical location of the CEO. Therefore, in describing the typologies of distant leadership above, we labeled Grant as a virtually-close leader in terms of his interaction with his direct subordinate leaders. However, nonimmediate followers of Grant would have perceived him as an avuncular leader, as could be the case for other high-level leaders.

Levels of analysis and distance

Bass and Avolio (1993) argued that the behaviors described in the FRLT can impact three levels of analysis: (a) the micro level, that is, the impact of leadership on immediate followers, (b) the macro level, that is the impact of leadership on organizations, and (c) meta level, that is, the impact of leadership on large social systems. However, not much research has uncovered the 
level of analysis at which the leadership phenomenon may operate. As mentioned by Waldman and Yammarino (1999), the confusion surrounding leader outcomes has stemmed because "organizational behavior theorists generally have confined leadership and its effects to the individual, dyadic, or small group levels of analysis" (p. 266). Following Klein, Dansereau and Hall (1994), Waldman and Yammarino argued that leader outcomes may be evident across various levels of analysis, measurement, and management, depending on leader hierarchical level. Waldman and Yammarino argued that levels of analysis refers to the level at which theoretical constructs are being measured. For example, leader behavior can be viewed at the individual level but may impact individual, group, or organizational levels of analysis. They referred to levels of measurement reflecting the precision of measurement required to ensure that the effects operate at the assumed level. Finally, levels of management refer to hierarchical levels ranging from supervisory level to strategic leadership.

Klein and House (1998) argued that charismatic leadership has an individual and group level effect. They stated further that the more charismatic leaders treat the followers homogenously, the more the effects of charisma will be evident on a group level. Following Howell and Shamir (1998), it is apparent that they failed to make a distinction between hierarchical leadership levels, or to take social distance into consideration, which could explain why the outcomes of leadership could vary from the individual to the group level of analysis.

Leader hierarchical level is a defining element implicating the level of analysis at which leader outcomes will be evident. Although leader hierarchical level may not necessarily cause leader distance (i.e., a high-level leader could interact individually with followers and reduce social distance, as with Alexander the Great), we would expect a moderate correlation between leader distance and leader hierarchy. For instance, a collective-level impact would be more 
prevalent in leaders who primarily have interactions with followers at the group level (e.g., socially and virtually-distant leaders), or where hierarchical level and physical distance (i.e., structural organizational characteristics) may prevent high-level leaders from interacting individually and frequently with low-level followers (e.g., avuncular, manor house, and distal leaders). However, an individual level impact would be more prevalent in leaders who primarily interact with followers at the individual level (e.g., proximal, "hands-off" and virtually-close leadership).

Yagil (1998) for example, theorized and found that socially (and physically) distant leaders impacted group-level efficacy more than they did individual-level efficacy, because socially-distant leaders have more information on the group than the individuals comprising the group. Yagil also demonstrated that socially (and physically) close leaders have an impact on individual-level efficacy because they custom-design their behaviors towards individual followers. Thus, our understanding of leader distance necessitates understanding the level of analysis at which leader outcomes should be measured.

Following the above discussions, and for the development of a parsimonious model, we grouped the eight typologies of distance into three broad classes, depending on the level of analysis at which the leader's behavior is theoretically evident. Class 1 comprises proximal, "hands off," and virtually-close leadership. These types of leaders are socially close to followers and, because of their close physical proximity or high frequency of contact, have individualized and direct interactions with followers. Leader outcomes are visible at the individual level of analysis. Class 2 comprises socially and virtually-distant leaders. Here, leadership operates at the group level because of leader social (and physical) distance. Class 3 comprises avuncular, manor house, and distal leadership. The primary commonality in this case is that leaders cannot 
maintain frequent and direct interaction with followers, and are either socially and/or physically distant. Depending on the leaders' hierarchical level, Class 3 leaders will either (a) have individual or group-level interaction with subordinate leaders who emulate the leader's behavior and, in turn, interact with followers on an individual or group level; or (b) they will interact homogenously at the group level with followers; or (c) both (a) and (b). The role-modeling of the active components of a leader's behavior (i.e., transformational and constructive transactional leadership) has been referred to as the "cascading effect" as demonstrated empirically by Bass, Waldman, Avolio, and Bebb (1987) (for further discussion on the cascading effect see Klein \& House, 1998; Rainey \& Watson, 1996; Shamir et al., 1993; Shamir, Zakay, Brainin, \& Popper, 2000; Yammarino, 1994).

Proposition 5: The level of analysis at which the effect of leadership is evident will vary as a function of leader-follower distance.

Proposition 6: Outcomes of "Class 2"leaders on immediate followers or of "Class 3" leaders on indirect followers will be more evident at the group level of analysis than at the individual level of analysis.

Proposition 7: Outcomes of "Class 1" leaders on immediate followers will be more evident at the individual level of analysis than at the group level of analysis.

Proposition 8: Subordinate leaders of active leaders will role-model their leaders' behaviors.

Antecedents of the emergence of leader distance

In this section, we review contextual variables that theoretically cause the dimensions of leader distance to emerge. Whether the actual leader distance that is prevalent in a certain context is equal to follower's expectations of how much distance a leader should maintain depends on 
whether the leader-follower distance is complementary to the contextual condition in which leadership is viewed. In other words, the behavior of a leader is successful to followers if the behavior matches followers' expected leader prototypes (see Lord, Foti, \& De Vader's 1984).

Apart from the structural characteristics of the organization (e.g., the physical design of the organization and physical layout of work areas) that may affect the degree of physical distance that emerges (Napier \& Ferris, 1993), we describe four factors that could theoretically affect the degree to which the three distance dimensions could emerge. We present each of the factors separately; however, it is probable that the factors could interact in determining total leader distance.

\section{$\underline{\text { Span of control }}$}

The leaders' span of control could theoretically affect the degree of interaction with followers (Napier \& Ferris, 1993). For instance, Judge and Ferris (1993) argued that a large span of control is associated with less leader-follower contact, because it theoretically becomes increasingly difficult for the leader to spend more time with his/her followers. According to Bass (1998), when leaders supervise a greater number of followers they may be obliged to use more management-by-exception behaviors, which is a less active form of leadership than is transformational or constructive transactional leadership. Furthermore, a large span of control could be associated with larger social distance, because the leader would treat followers more homogenously and with less individualized attention.

Proposition 9: Span of leader control will be negatively associated with leader-follower interaction and positively associated with social distance. 


\section{$\underline{\text { Task characteristics and follower abilities }}$}

Based on the propositions of House's (1971) path-goal theory, the degree of leaderfollower interaction—whether directive or developmentally centered—is contingent on task characteristics and follower abilities. Howell et al. (1997) made a similar point. House and Mitchell (1974) noted, "when goals and paths to desired goals are apparent because of the routine nature of the task, clear group norms or objective controls of the formal authority systems, attempts by the leader to clarify paths and goals will be both redundant and seen by subordinates as imposing unnecessary close control” (p. 88). House and Mitchell also noted "Where the subordinate's perceived ability is high, [leader directiveness and coaching behavior] is likely to have little positive effect on the motivation of the subordinate and to be perceived as excessively close control" (p. 87). For example, Cardinal and Hatfield (2000) demonstrated that research facilities of pharmaceutical companies were more innovative when distally located from corporate headquarters, because top management did not meddle in the work of highly qualified research scientists.

Proposition 10: High follower ability and clear follower task demands will be negatively associated with perceived leader-follower interaction frequency.

\section{$\underline{\text { National and organizational culture }}$}

As discussed before, followers accept leaders as a function of followers' perceptions of the leaders' behaviors, and whether these behaviors match the followers' expected leader prototypes in certain contexts. Context must therefore be taken into consideration because it is likely that implicit leader prototypes will vary depending on cultural context (Gerstner \& Day, 1994; Lord, Brown, Harvey, \& Hall, 2001). As noted by House, Wright, and Aditya (1997), 
implicit theories allow members of a common group to "constrain, moderate, or facilitate the exercise of leadership, the acceptance of leaders, and the perception of leaders as influential, acceptable, and effective" (p. 600). Therefore, individuals (and leaders) that are bound together by a common culture will have similar implicit notions of how leaders should behave.

Hofstede (1980) defined culture to be "the collective programming of the mind which distinguishes the members of one human group from another" (p. 25). He offered a similar definition of organizational culture, which he defined as being "the collective programming of the mind which distinguishes the members of one organization from another," including the history of the organization, its rites and rituals (pp. 179-180). Because national and organizational culture operate in a similar manner in terms of how they influence individuals, and because organizational culture is in part a function of national culture (e.g., see Bochner \& Hesketh, 1994; Hofstede, 1980; Offermann \& Hellmann, 1997; Pavett \& Morris, 1995; Smith, Dugan \& Trompenaars, 1996; Van Muijen \& Koopman, 1994), below we will describe only how national culture may affect the degree to which leader distance is prevalent in the organization.

Den Hartog, House, Hanges, Ruiz-Quintanilla, and Dorfman (1999) found that various elements of transformational/charismatic leadership were perceived as effective across 62 cultures. Following Bass (1997), Antonakis and House (in press) argued that transformational and transactional leadership may indeed be universal; however, the manner in which directive and participative leader behaviors are enacted will vary by culture, and will depend in part, on power distance and collectivism (see Hofstede, 1980, 1991). Power distance (PD) refers to how society deals with and views inequalities in power distribution among the members of society. Inequalities in societies can occur in terms of social status, prestige, power, and rights. Hofstede's definition of power distance thus appears to largely parallel our definition of social 
distance. Hofstede found that organizations of high PD cultures tended to be more centralized and relied on more hierarchical levels than did organizations in low PD cultures. Also, high PD leaders were more autocratic and directive than were low PD leaders.

Individualism is the degree to which members of a group are individualistic in their goals and objectives in life. Collectivism refers to the extent that individual goals are more aligned with those of the collectivity (Hofstede, 1980; 1991). Because of the high correlation between power distance and collectivism $(r=.76$; Hofstede, 1980, p. 221), from a practical perspective, Triandis (1993) argued that the two dimensions could be assumed to have a common effect. Triandis stated that collectivist societies value hierarchy, whereas individualists value autonomy. The former value collective goals and interdependency, whereas the latter value individual goals and independence. Thus, it follows that in high power-distance/collectivist societies, leaders are more autocratic, directive, and inaccessible, and organizations are more mechanistic and hierarchically tall. Low PD cultures should, however, support more democratic, participative, and accessible leaders, and more organic and flat organizational structures (e.g., see Bakhtari, 1995; Bochner \& Hesketh, 1994; Javidan \& House, 2001; Mead, 1967; Offermann \& Hellmann, 1997; Pavett \& Morris, 1995; Yammarino \& Jung, 1998).

In terms of the level of analysis at which the effect of leadership will be evident, and following the above reasoning, Yammarino and Jung (1998) proposed that high PD cultures “adopt a person-group (leader-followers) model—an independent higher status person of power (leader) essentially directs through equal treatment a group of loyal followers who accept this status difference" (p. 54). In other words, the effect of leadership is evident at the group level of analysis resulting from the homogenous behavior of leaders towards followers. Yammarino and Jung argued that low PD cultures would value leader-follower relationships that are "dyadic and 
balanced . . . because they are not predicated on unequal or differing power status" (p. 54). In other words, given the individualized contact between leaders and their followers, the effect of leadership is evident at the individual level of analysis.

Following the above discussion, leaders in high PD and collectivist societies would therefore maintain a higher degree of social distance with their followers and treat them more homogenously. Moreover, the level of analysis at which leader outcomes will be visible is at the group level of analysis. Leaders in low PD and individualistic societies would maintain a lower degree of social distance with their followers and treat followers individually. Thus, the level of analysis at which leader outcomes will be visible is at the individual level of analysis.

Proposition 11: High power distance (and collectivism) will be positively associated with high social distance.

Proposition 12: In high power distance (and collectivist) cultures, the level of analysis at which leadership outcomes will be evident is at the group level of analysis.

Proposition 13: In low power distance (and individualist) cultures, the level of analysis at which leadership outcomes will be evident is at the individual level of analysis.

\section{$\underline{\text { Leader and follower implicit motives }}$}

Implicit (nonconscious) motives refer to conditions that individuals wish to bring about or avoid (Winter, John, Stewart, Klohnen, \& Duncan, 1998). Three types of implicit motives guide behavior (McClelland, 1975): (a) need for power, which refers to the degree to which individuals wish to influence or have an impact on other individuals or social systems; (b) need for achievement, which refers the degree to which individuals wish to surpass standards of performance and to achieve excellence; and (c) need for affiliation, which refers to the degree to which individuals wish be friendly with others and their desire to be affiliated with a social 
group. Leader and follower motives could theoretically affect the distance that is prevalent in leader-follower relations. Following Howell et al. (2002), it is possible that the amount of distance tolerated or desired by leaders may be linked to their motive patterns.

Leaders with a high need for affiliation would theoretically strive to minimize social distance with followers. Because "someone who is eager for power is less likely to be friendly with others," McClelland (1975, p. 322) argued that need for power is negatively correlated with need for affiliation. Thus, leaders with a high need for power would probably be socially distant from their followers. Achievement-oriented leaders have been found to be effective in small task-oriented groups and at low levels of management (Litwin \& Stringer, 1968; McClelland, 1962; McClelland \& Boyatzis, 1982) and would tend to micromanage (Winter, 2002). Thus, we would expect achievement-oriented leaders to maintain high frequency of contact with followers.

As regards follower motives, leader behavior is viewed as satisfactory to followers if the behavior is instrumental to follower satisfaction or success (House \& Dessler, 1994). Thus, an element of follower satisfaction related to leadership may be the fulfillment of implicit follower motives, because followers "with high needs for affiliation and social approval would see friendly, considerate leader behavior as an immediate source of satisfaction" (House \& Dessler, p. 31). Thus, these types of followers would expect low social distance from their leader. It would follow that leaders, would in turn, attempt to satisfy follower expectations by behaving more or less socially close or distant with followers.

Proposition 14: High need for power leaders will maintain greater social distance from followers than will low need for power leaders.

Proposition 15: High need for affiliation leaders will maintain less social distance from followers than will low need for affiliation leaders. 
Proposition 16: High need for achievement leaders will maintain higher interaction frequency with followers than will low need for achievement leaders.

Proposition 17: High need for affiliation followers would expect their leaders to act less socially distant than would low need for affiliation followers.

\section{A MODEL OF LEADER DISTANCE}

Based on Waldman and Yammarino's (1999) model describing the socially close and distant leadership of high-level (CEO) leaders, and following our propositions, we have developed an integrated cross-level model of leader distance (see Figure 1). Causal relations in solid-line arrows follow our propositions and are labeled according to the relevant proposition. As suggested in the model, the typology of leader distance that emerges is associated with leader behavior affecting the individual and/or group level of analysis. The level at which leader outcomes are evident determines how the leader is legitimized and the type of charisma that will emerge. The latter, in turn, leads to follower identification with (and trust in) the leader. The model is based on the assumptions that the leadership presented in all cases is effective and authentic (see Avolio, 1999; Bass, 1998), and that the role-modeling behaviors of subordinate leaders support and emulate the behaviors of the leader.

[Insert Figure 1 about here]

As discussed before, what constitutes a follower is important in terms of which typology is used to describe a leader. For example, indirect followers may see the leader as a distal leader; however, direct followers may see the leader as a proximal leader. Thus, in the case of Class 3 leaders, leader outcomes may be evident at the individual level of analysis (i.e., on subordinate leaders, following Proposition 7) or at the group level of analysis (i.e., on subordinate leaders or on indirect followers, following Proposition 6). Thus, the direct effect of leaders on subordinate 
leaders could also be considered in the model, linking subordinate leader interaction with direct evaluation of the leader (as per Proposition 2a) or with attributions of the leader (as per Proposition 3a), as depicted with the two dotted-lined arrows in the center of the figure. However, for simplicity, we will exclude leader outcomes on subordinate leaders.

As suggested in the model, the leader's influence flows from the three following sources: (a) from individual-level relations that the leader has with immediate followers as with Class 1 leaders; (b) from individual or group-level relations that the subordinate leaders have with followers, resulting from the cascading effect leader behaviors have on distant followers through the leader's subordinate leaders, as with Class 3 hierarchically high level leaders; (c) from grouplevel relations that the leader has with followers as with Class 2 and 3 leaders.

Followers who can directly evaluate a leader's behaviors and performance will accept the leader based on their direct observations and intimate knowledge of the leader. Because the leader has an effect at the individual level of analysis, as a result of the leader's relational charisma, self-concepts will be implicated at the individual level, leading to identification with, and "close" trust in, the leader.

Attributional charisma will emerge from attributions of the leader or subordinate leaders that followers make based on the leaders' homogenous behaviors towards followers, the impression management techniques they use, and how followers perceive the leader's socialized charisma. Because the leader has an effect at the group level of analysis, self-concepts will be implicated at the collective level leading to social identification and identification with, and "distant trust in, the leader.

Finally, as has been established empirically, followers of charismatic leaders will exert more effort in ensuring that organizational goals are realized than will followers of 
noncharismatic leaders (see Avolio, 1999; Bass, 1990, 1998 for reviews). However, this effort needs to be coordinated. According to Katz and Kahn (1978), the roles of leaders are to ensure the systemic functioning of their organizations by synthesizing and integrating its human resources, and by compensating for deficiencies in the system and changes in the environment.

Similarly, Waldman and Yammarino (1999) argued that due to the inherent conflicting nature of certain organizational processes, the role of top-level leaders is to use their vision and values to ensure that organizational resources are used to achieve the organization's intended objectives. The strategic coordination function of top-level leaders is integral to coordinated organizational effectiveness; however, efforts that lead to organizational effectiveness are not restricted to top-level leaders and can be evident throughout the hierarchy of the organization. At lower hierarchical levels, values and vision also play a role, but different instrumental leader behaviors (e.g., path-goal facilitation, and outcome monitoring), will contribute to organizational performance (Antonakis \& House, in press).

\section{DISCUSSION}

The central thesis of this article was that total leader distance plays an important role in explaining the leadership influencing process and how trust and identification in the leader develop. Our intention was to build on previous frameworks that used distance as a central theoretical concept. Our study was mainly explanatory; we discussed how intermediate outcomes of leadership were a function of total leader distance, and how leaders' behaviors may affect various levels of analysis. Our intention was to demonstrate that functional distance, as defined by Napier and Ferris (1993), is not a necessary condition for effective leadership. Rather, leader success is contingent on actively managing the degree of distance leaders maintain from 
followers, depending on contextual factors. That is, leader-follower distance can contribute to or detract from leader effectiveness.

Beyond the theoretical considerations in our article there are practical implications of physical distance that we discuss briefly below. As noted by Howell et al. (1997), physical distance in organizations will become increasingly prevalent as firms internationalize, and because of the increase in amount of service-sector employees working from home. Our closing remarks will thus focus on the implications of physical distance on leaders. As discussed previously, physical distance creates conditions that may not be conducive for leadership as it makes it difficult for leaders and followers to interact with each other. However, advances in communications technology can facilitate communication that occurs between leaders and followers that previously was hindered by physical distance. Situations in which the leader is physically distant from followers who require frequent interaction with the leader necessitates that either the leader can deliver the interaction that followers require using communications technology or that there are adequate substitutes for leadership that can allow followers to be effective without the leader. For example, Howell et al. (1997) noted that feedback generated by information technology systems, and closely-knit teams can provide appropriate substitutes for leadership.

Virtual communication may bring several advantages and disadvantages. Avolio, Kahai, Dumdum, and Sivasubramaniam (2001) noted that modern technologies "have enabled organizations to rapidly form teams that are not restricted by geography, time, or organizational boundaries" (p. 337). Avolio et al. (2001) also argued that virtual leaders, whose communication is mediated by electronic means, can create conditions which induce followers to transcend their self-interest for the good of the group. We have some evidence that leadership, and in particular 
certain styles of leadership (e.g., transformational leadership), can have an impact on followers when leader-follower interaction is mediated by technology, and that individuals can perceive differences in leadership styles in computer-mediated communication environments (e.g., Kahai, Sosik, \& Avolio, 1997; Sosik, 1997; Sosik, Avolio, \& Kahai, 1997; Sosik, Avolio, Kahai, \& Jung, 1998).

Another advantage of technology-mediated environments using asynchronous communication systems (e.g., electronic brainstorming) is that it "frees participants from the social rules typically associated with face-to-face communication (e.g., waiting for someone to finish speaking before you speak), as well as cognitive constraints (e.g., thinking along narrow lines)' (Kahai et al., 1997, p. 125). Furthermore, Weisband and Atwater (1999) stated that virtual communication may eliminate affect bias of others because individuals lack cues and information associated with face-to-face interactions.

However, virtual leader-follower contexts will create conditions that are increasingly challenging for leaders to manage. Shamir (1999) noted that it is unclear whether individuals can identify with and trust virtual leaders due to the cold, deemphasized social and human context of interaction in such situations. As noted by Daft and Lengel (1984), the medium of information (e.g., face-to-face, telephone, etc.) affects the richness of information such that highly complex problems are best understood by transmitting information using very rich information media (e.g. face-to-face). Information richness also affects how a message is delivered. For example, Awamleh and Gardner (1999) suggested that, although vision content plays a role in promoting a better image of the leader and charismatic attributions that followers make of the leader, the way in which a leader delivers his or her vision has a greater impact on follower perceptions than does the actual content of the message and other organizational performance cues. They noted 
further "a weak delivery acts like 'noise' which undermines the impact of the leader's speech, no matter how inspirational its content may be" (p. 360). Thus, communicating at a distance may make it especially difficult for leaders to be inspirational, unless followers can see and hear the leader. Indeed, Hitler disliked using the telephone because he felt that it "minimized his magnetism" (Kegan, 1987, p. 327).

Shamir and Ben-Ari (1999) further noted that it would be very difficult for virtuallydistant leaders to inspire confidence in followers using symbolic gestures, especially through the display of exemplary acts and through role modeling. Sosik, Avolio, and Kahai, (1997) made a similar point and stated that nonverbal cues which characterize an important element of charismatic leadership would be restricted if leaders-follower interaction was mediated solely by written electronic means. Also, as indicated by Weisband and Atwater (1999) social interactions in virtual teams typically lack nonverbal cues, and thus the degree to which interpersonal relations may develop between individuals is reduced.

Interactions that occur in virtual team contexts also complicate how trust may be developed. As we discussed previously, whether trust emerges, and what type of trust that emerges depends on various factors. Jarvenpaa and Leidner (1999) argued that trust between organizational players in virtual teams (i.e., geographically displaced teams that have been assembled for short-term projects) does not operate in the same manner virtually as it does in face-to-face encounters. In virtual settings trust has more of a temporary nature and needs to be formed swiftly, that is, "members act as if trust is present from the start" (Jarvenpaa, Knoll \& Leider, 1998, p. 56).

Thus, identifying responsibilities of team members, maintaining frequent contact, and promoting team-related aims may lead to increased trust (Jarvenpaa \& Leider, 1999), suggesting 
that the role of a leader in a virtual team context plays an important role. Furthermore, Jarvenpaa et al. (1998) argued that because virtual team members may not know each other, and because of communication channels that are impersonal (e.g., e-mail), "Trust in a virtual-team context might therefore be more strongly related to ability and integrity, and less to benevolence" (p. 32). They suggest the use of team exercises to increase perception of ability and integrity (but also of benevolence), by the exchange of information early in the collaboration.

In conclusion, we hope that leader distance will be considered in future theoretical frameworks and that empirical work will result, in part, from our review. The distance that a leader maintains from followers appears to be a defining element of the leadership influencing process. It is our hope that we have brought the concept of leader distance a little closer.

\footnotetext{
${ }^{1}$ Note: Waldman and Yammarino did not specifically address physical proximity; however, our explanation of manor house leaders rests on the assumption that the leader is physically co-located, as with many cases of highlevel strategic leaders. In the event that a strategic-level leader is distally located, then the befitting label becomes distal leadership, which, as discussed from a levels-of-analysis perspective, has the same outcome as manor house leadership.
} 


\section{REFERENCES}

Awamleh, R., \& Gardner, W. L. (1999). Perceptions of leader charisma and effectiveness: The effects of vision content, delivery, and organizational performance. The Leadership Quarterly, 10(3), 345-373.

Antonakis, J. (2001). The validity of the transformational, transactional, and laissez-faire leadership model as measured by the Multifactor Leadership Questionnaire (MLQ5X). Dissertation Abstracts International, (University Microfilms No. 3000380).

Antonakis, J., Hedlund J., Pretz, J. E., \& Sternberg, R. J. (2002). Exploring the nature and acquisition of tacit knowledge for military leadership. Army Research Institute for the Behavioral and Social Sciences. Research Note 2002-04. Alexandria, VA.

Antonakis, J., \& House, R. J. (in press). An analysis of the full-range leadership theory: The way forward. In B. J. Avolio \& F. J. Yammarino (Eds.), Transformational and Charismatic Leadership: The Road Ahead. JAI Press.

Antonakis, J., \& House, R. J. (2002) A reformulated full-range leadership theory. (Manuscript in preparation).

Ashford, S. J., \& Cummings, L. L. (1985). Proactive feedback seeking: The instrumental use of the information environment. Journal of Occupational Psychology, 58, 67-79.

Ashforth, B. E., \& Mael, F. (1989). Social identity theory and the organization. Academy of Management Review, 14(1), 20-39.

Aronson, E., Willerman, B., \& Floyd, J. (1966). The effect of pratfall on increasing interpersonal attractiveness. Psychonomic Science, 4(6), 227-228.

Avolio, B. J. (1999). Full leadership development: Building the vital forces in organizations. Thousand Oaks, CA: Sage Publications. 
Avolio, B. J., Kahai, S., Dumdum, R., \& Sivasubramaniam, N. (2001). Virtual teams: Implications for e-leadership and team development. In M. London (Ed.), How people evaluate others in organizations (pp. 337-358). Mahwah, NJ: Lawrence Erlbaum Associates.

Avolio, B. J., Kahai, S., \& Dodge, G. E. (2001). E-leadership: Implications for theory, research, and practice. The Leadership Quarterly, 11(4), 615-668.

Bakhtari, H. (1995). Cultural effects on management style. International Studies of Management and Organization, 25(3), 97-118.

Bass, B. M. (1985). Leadership and performance beyond expectations. New York: The Free Press.

Bass, B. M. (1990). Bass \& Stogdill's handbook of leadership (3rd ed.). New York: The Free Press.

Bass, B. M. (1997). Does the transactional-transformational leadership paradigm transcend organizational boundaries? American Psychologist, 52(2), 130-139.

Bass, B. M. (1998). Transformational leadership: Industrial, military, and educational impact. Mahwah, NJ: Lawrence Erlbaum Associates.

Bass, B. M., \& Avolio, B. J. (1993). Transformational leadership: A response to critiques. In M. M. Chemers, \& R. Ayman (Eds.), Leadership theory and research: Perspectives and directions (pp. 49-80). San Diego: Academic Press.

Bass, B. M., \& Avolio, B. J. (Eds.). (1994). Improving organizational effectiveness through transformational leadership. Thousand Oaks, CA: Sage Publications.

Bass, B. M., \& Avolio, B. J. (1995). MLQ Multifactor leadership questionnaire for research. Redwood City, CA: Mindgarden. 
Bass, B. M., \& Avolio, B. J. (1997). Full range leadership development: Manual for the multifactor leadership questionnaire. Palo Alto, CA: Mindgarden.

Bass, B. M, Waldman, D. A., Avolio, B. J., \& Bebb, M. (1987). Transformational leadership and the falling dominoes effect. Group \& Organization Studies 12(1), 73-87.

Blake, R. R., \& Mouton, J. S. (1964). The managerial grid. Houston: Gulf Publishing Group.

Bochner, S., \& Hesketh, B. (1994). Power distance, individualism/collectivism, and job-related attitudes in a culturally diverse work group. Journal of Cross-Cultural Psychology, 25(2), 233-257.

Bogardus, E. S. (1927). Leadership and social distance. Sociology and Social Research, 12, 173178.

Bogardus, E. S. (1928). Occupational distance. Sociology and Social Research, 13, 73-81.

Burns, J. M. (1978). Leadership. New York: Harper \& Row.

Burrows, L., Munday, R., Tunnell, J., \& Seay, R. (1996). Leadership substitutes: Their effects on teacher organizational commitment and job satisfaction. Journal of Instructional Psychology, 23, 3-8.

Cardinal, L. B., \& Hatfield, D. E. (2000). Internal knowledge generation: The research laboratory and innovative productivity in the pharmaceutical industry. Journal of Engineering and Technology Management, 17, 247-271.

Conger, J. A. (1999). Charismatic and transformational leadership in organizations: An insider's perspective on these developing streams of research. The Leadership Quarterly, 10(2), $145-179$.

Conger, J. A., \& Kanugo, R. N. (1998). Charismatic leadership in organizations. Thousand Oaks, CA: Sage Publications. 
Daft, R. L., \& Lengel, R. H. (1984). Information Richness: A new approach to managerial behavior and organizational design. In B. M. Staw \& L. L. Cummings (Eds.), Research in Organizational Behavior, 6, 191-233. Greenwich, CT: JAI Press.

Den Hartog, D. N., House, R. J., Hanges, P. J., Ruiz-Quintanilla, S. A., \& Dorfman, P. W. (1999). Culture specific and cross-cultural generalizable implicit leadership theories: Are attributes of charismatic/transformational leadership universally endorsed? The Leadership Quarterly, 10(2), 219-256.

Eden, D., \& Leviatan, U. (1975). Implicit leadership theory as a determinant of the factor structure underlying supervisory behavior scales. Journal of Applied Psychology, 60(6), 736-741.

Etzioni, A. (1961). A comparative analysis of complex organizations. New York: The Free Press.

Fiedler, F. E. (1967). A theory of leadership effectiveness. New York: McGraw-Hill.

Frank, A. W. (1974). Social distance. In Encyclopedia of Sociology (pp. 269-270). Guilford, CT: The Dushkin Publishing Group.

Gardner, J. W. (1990). On leadership. New York: The Free Press.

Gardner, W. L., \& Avolio, B. J. (1998). The charismatic relationship: A dramaturgical perspective. Academy of Management Review 23(1), 32-58.

Gerstner, C. R., \& Day, D. V. (1994). Cross-cultural comparisons of leadership prototypes. The Leadership Quarterly, 5(2), 121-134.

Halpin, A. W., \& Winer, B. J. (1957). A factorial study of the leader behavior descriptions. In R. M. Stogdill, \& A. E. Coons (Eds.), Leader behavior: Its description and measurement (pp. 39-51). Research Monograph Number 88, Ohio State University Bureau of Business Research. 
Hede, A., \& Wear, R. (1996). Dimensions of political and organisational leadership. In K. W. Parry (Ed.), Leadership research and practice: Emerging themes and new challenges (pp. 65-75). Warriewood, Australia: Business \& Professional Publishing.

Hofstede, G. (1980). Culture's consequences: International differences in work-related values. Beverly Hills, CA: Sage Publications.

Hofstede, G. (1991). Cultures and organizations: Software of the mind. Berkshire, England: McGraw-Hill Book Company.

House, R. J. (1971). A path-goal theory of leadership effectiveness, Administrative Science Quarterly, 16, 321-328.

House, R. J. (1977). A 1976 theory of charismatic leadership. In J. G. Hunt, \& L. L. Larson (Eds.), Leadership: The cutting edge (pp. 189-207). Carbondale: Southern Illinois University Press.

House, R. J., \& Dessler, G. (1994). The path-goal theory of leadership: Some post hoc and a priori tests. In R. J. Hunt, \& L. L. Larson (Eds.), Contingency approaches to leadership (pp. 29-55). Carbondale: Southern Illinois University Press.

House, R. J., \& Mitchell, T. R. (1974). Path-goal theory of leadership. Journal of Contemporary Business, 3(4), 81-97.

House, R. J., Wright, N. S., \& Aditya, R. N. (1997). Cross-cultural research on organizational leadership: A critical analysis and a proposed theory. In P. C. Earley, \& M. Erez (Eds.), New perspectives on international industrial/organizational psychology (pp. 535-625). San Francisco: New Lexington Press. 
Howell, J. M., \& Avolio, B. J. (1993). Transformational leadership, transactional leadership, locus of control, and support for innovation: Key predictors of consolidated-business-unit performance. Journal of Applied Psychology 78(6), 891-902.

Howell, J. M., \& Hall-Merenda, K. (1999). The ties that bind: The impact of leader-member exchange, transformational and transactional leadership, and distance on predicting follower performance. Journal of Applied Psychology, 84, 680-694.

Howell, J. M., Neufeld, D. J., \& Avolio, B. J. (1998). Leadership at a distance: The effects of physical distance, charismatic leadership, and communication style on predicting business unit performance. Unpublished manuscript, University of Western Ontario, Canada.

Howell, J. M., Neufeld, D. J., \& Avolio, B. J. (2002). A longitudinal study of the effects of transformational and contingent reward leadership, communication style, and physical distance on business unit performance. (Manuscript submitted for publication).

Howell, J. M., \& Shamir, B. (1998). Pockets of fire: The potential and the risk. In F. Dansereau \& F. J. Yammarino (Eds.), Leadership: The multiple-level approaches (pp. 37-44). Stamford, CT: Jai Press.

Howell, J. P., \& Bowen, D. E, Dorman, P. W., \& Kerr, S. (1990). Substitutes for leadership: Effective alternatives to ineffective leadership. Organizational Dynamics, 19(1), 21-38. Howell, J. P., Bowen, D. E., Dorfman, P. W., Kerr, S., \& Podsakoff, P. M. (1997). Substitutes for leadership: Effective alternatives to ineffective leadership. In R. P. Vecchio (Ed.). Leadership: Understanding the dynamics of power and influence in organizations (pp. 381-395). Notre Dame, IN: University of Notre Dame Press.

Hunt, J. G. (1991). Leadership: A new synthesis. Newbury Park, CA: Sage Publications. 
Hunt, J. G. (1999). Transformational/charismatic leadership's transformation of the field: An historical essay. The Leadership Quarterly, 10(2), 129-144.

Jarvenpaa, S. L., \& Leidner, D. E. (1999). Communication and trust in global virtual teams. Organization Science, 10(6), 791-815.

Jarvenpaa, S., Knoll, K., \& Leidner, D. (1998). Is anybody out there? Antecedents of trust in global virtual teams. Journal of Management Information Systems, 14, 29-64.

Javidan, M., \& House, R. J. (2001). Cultural acumen for the global manager: Lessons from Project GLOBE. Organizational Dynamics, 29(4), 289-305.

Jermier, J. M., Slocum, J. W., Fry, L. W., \& Gaines, J. (1991). Organizational subcultures in a soft bureaucracy: Resistance behind the myth and façade of an official culture. Organizational Science, 2(2), 170-194.

Judge, T. A., \& Ferris, G. R. (1993). Social context of performance evaluation decisions. Academy of Management Journal, 36(1), 80-105.

Kahai, S. S., Sosik, J. J., \& Avolio, B. J. (1997). Effects of leadership style and problem structure on work group process and outcomes in an electronic meeting system environment. Personnel Psychology, 50(1), 121-146.

Katz, D., \& Kahn, R. L. (1978). The social psychology of organizations. New York: John Wiley \& Sons.

Kegan, J. (1987). The mask of command. New York: Penguin Books.

Kerr, S., \& Jermier, J. M. (1978). Substitutes for leadership: Their meaning and measurement. Organizational Behavior and Human Performance, 22, 375-403. 
Klein, K. J., \& House, R. J. (1998). On fire: Charismatic leadership and levels of analysis. In F. Dansereau \& F. J. Yammarino (Eds.), Leadership: The multiple-level approaches (pp. 321). Stamford, CT: Jai Press.

Klein, K. J., Dansereau, F., \& Hall, R. J. (1994). Levels issues in theory development, data collection and analysis. Academy of Management Review, 19(2), 195-229.

Litwin, G. H., \& Stringer, R. A., Jr. (1968). Motivation and organizational climate. Boston: Harvard Business School Press.

Lord, R. G., Foti, R. J., \& De Vader, C. L. (1984). A test of leadership categorization theory: Internal structure, information processing, and leadership perceptions. Organizational Behavior and Human Performance, 34, 343-378.

Lord, R. G., Brown, D. J., Harvey, J. L., \& Hall, R. J. (2001). Contextual constraints on prototype generation and their multilevel consequences for leadership perceptions. The Leadership Quarterly, 12, 311-338.

Lowe, K. B., Kroeck, K. G., \& Sivasubramaniam, N. (1996). Effectiveness correlates of transformational and transactional leadership: A meta-analytic review of the literature. The Leadership Quarterly, 7(3), 385-425.

Mayer, R. C., Davis, J. H., \& Schoorman, F. D. (1995). An integrative model of organizational trust. Academy of Management Review, 20(3), 709-734.

McClelland, D. C. (1962). Business drive and national achievement. Harvard Business Review, 40(4), 99-112.

McClelland, D. C. (1975). Power: The inner experience. New York: Halsted Press.

McClelland, D. C., \& Boyatzis, R. E. (1982). Leadership motive pattern and long-term success in management. Journal of Applied Psychology, 67(6), 737-743. 
Mead, R. D. (1967). An experimental study of leadership in India. Journal of Social Psychology, 72(1), 35-43.

Meindl, J. R. (1990). On leadership: An alternative to the conventional wisdom. In B. M. Staw \& L. L. Cummings (Eds.), Research in Organizational Behavior, 12, 159-203. Greenwich, CT: JAI Press.

Meindl, J. R., \& Ehrlich, S. B. (1987). The romance of leadership and the evaluation of organizational performance. Academy of Management Journal, 30(1), 91-109.

Meyer, A. D., Tsui, A. S., \& Hinings, C. R. (1993). Configural approaches to organizational analysis. Academy of Management Journal, 36(6), 1175-1195.

Napier, B. J., \& Ferris, G. R. (1993). Distance in organizations. Human Resource Management Review, 3(4), 321-357.

Offermann, L. R., \& Hellmann, P. S. (1997). Culture's consequences for leadership behavior: National values in action. Journal of Cross-Cultural Psychology, 28(3), 342-351.

Park, R. E. (1924). The concept of social distance. Journal of Applied Sociology, 8(5), 339-344.

Pastor J. C., Meindl, J. R., \& Mayo, M. C. (2002). A networks effects model of charisma attributions. Academy of Management Journal 45(2), 410-420.

Pavett, C., \& Morris, T. (1995). Management styles within a multinational corporation: A five country comparative study. Human Relations, 48(10), 1171-1191.

Podsakoff, P. M., MacKenzie, S. B., \& Bommer, W. H. (1996a). Transformational leader behaviors and substitutes for leadership as determinants of employee satisfaction, commitment, trust, and organizational citizenship behaviors. Journal of Management, 22(2), 259-298. 
Podsakoff, P. M., MacKenzie, S. B., \& Bommer, W. H. (1996b). Meta-analysis of the relationships between Kerr and Jermier's substitutes for leadership and employee job attitudes, role perceptions, and performance. Journal of Applied Psychology, 81(4), 380399.

Podsakoff, P. M., Todor, W. D., Grover, R. A \& Huber, V. L. (1984). Situational moderators of leader reward and punishment behaviors: Fact or fiction? Organizational Behavior and Human Performance, 34, 21-63.

Rainey, H. G., \& Watson, S. A. (1996). Transformational leadership and middle management: Towards a role for mere mortals. International Journal of Public Administration, 19(6), 763-800.

Roberts, N. C., \& Bradley, R. T. (1988). Limits of charisma. In J. A. Conger, \& R. N. Kanugo (Eds.), Charismatic leadership: The elusive factor in organizational effectiveness (pp. 253-275). San Francisco: Jossey-Bass Publishers.

Sashkin, M. (1988). The visionary leader. In J. A. Conger, \& R. N. Kanugo (Eds.), Charismatic leadership: The elusive factor in organizational effectiveness (pp. 122-160). San Francisco: Jossey-Bass Publishers.

Shamir, B. (1995). Social distance and charisma: Theoretical notes and an exploratory study. The Leadership Quarterly, 6(1), 19-47.

Shamir, B. (1999). Leadership in boundaryless organizations: Disposable or indispensable. European Journal of Work and Organizational Psychology, 8(1), 49-71.

Shamir, B., \& Ben-Ari, E. (1999). Leadership in an open army? Civilian connections, interorganizational frameworks and changes in military leadership. In Hunt, J. G., Dodge, 
G. E., \& Wong, L. (Eds.), Out-of-the-box leadership: Transforming the twenty-firstcentury army and other top-performing organizations. Stamford, CT: JAI Press.

Shamir, B., House, R. J., \& Arthur, M. B. (1993). The motivational effects of charismatic leadership: A self-concept based theory. Organization Science, 4(4), 577-594.

Shamir, B., Zakay, E., Brainin, E., \& Popper, M. (2000). Leadership and social identification in military units: Direct and indirect relationships. Journal of Applied Social Psychology, $30(3), 612-640$.

Smith, P. B., Dugan, S., \& Trompenaars, F. (1996). National culture and the values of organizational employees: A dimensional analysis across 43 nations. Journal of CrossCultural Psychology, 27(2), 231-264.

Smith, J. A., \& Foti, R. J. (1998). A pattern approach to the study of leader emergence. The Leadership Quarterly, 9(2), 147-160.

Sosik, J. J. (1997). Effects of transformational leadership and anonymity on idea generation in computer-mediated groups. Group and Organization Management 22(4), 460-487.

Sosik, J. J., Avolio, B. J., \& Kahai, S. S. (1997). Effects of leader style and anonymity on group potency and effectiveness in a group decision support system environment. Journal of Applied Psychology, 82, 89-103.

Sosik, J. J., Avolio, B. J., Kahai, S. S., \& Jung, D. I. (1998). Computer-supported work group potency and effectiveness: The role of transformational leadership, anonymity, and task interdependence. Computers in Human Behavior, 14(3), 491-511.

Triandis, H. C. (1993). The contingency model in cross-cultural perspective. In M. M. Chemers, \& R. Ayman (Eds.), Leadership theory and research: Perspectives and directions (pp. 167-188). San Diego: Academic Press. 
Uhl-Bien, M., Graen, G. B., \& Scandura, T. (2000). Implications of Leader-Member Exchange (LMX) for Strategic Human Resource Management Systems: Relationships as Social Capital for Competitive Advantage. In G. Ferris (Ed.), Research in Personnel and Human Resource Management, 18, 137-185. Greenwich, CT: JAI Press.

van Muijen, J. J, \& Koopman, P. L. (1994). The influence of national culture on organizational culture: A comparative study between 10 countries. European Work and Organizational Psychologist, 4(4), 367-380.

Waldman, D. A., \& Yammarino, F. J. (1999). CEO charismatic leadership: Levels-ofmanagement and levels-of-analysis effects. Academy of Management Review, 24(2), 266285.

Weisband, S., \& Atwater, L. (1999). Evaluating self and others in electronic and face-to-face groups. Journal of Applied Psychology, 84, 632-639.

Westley, F. R., \& Mintzberg, H. (1988). Profiles of strategic vision: Levesque and Iacocca. In J. A. Conger, \& R. N. Kanugo (Eds.), Charismatic leadership: The elusive factor in organizational effectiveness (pp. 161-212). San Francisco: Jossey-Bass Publishers.

White, R., \& Lippitt, R. (1968). Leader behavior and member reaction in three "social climates." In D. Cartwright, \& A. Zander. Group dynamics (pp. 318-335). New York: Harper \& Row Publishers.

Willner, A. R. (1984). The spellbinders: Charismatic political leadership. New Haven: Yale University Press.

Winter, D. G. (2002). The motivational dimensions of leadership: Power, achievement and affiliation. In R. E. Riggio, S. E. Murphy, \& F. J. Pirozzolo (Eds.), Multiple intelligences and leadership (pp. 119-138). Mahwah, NJ: Lawrence Erlbaum Associates. 
Winter, D. G., John, O. P., Stewart, A. J., Klohnen, E. C., \& Duncan, L. E. (1998). Traits and motives: Toward an integration of two traditions in personality research. Psychological Review, 105(2), 230-250.

Yagil, D. (1998). Charismatic leadership and organizational hierarchy: Attribution of charisma to close and distant leaders. The Leadership Quarterly, 9(2), 161-176.

Yammarino, F. J. (1994). Indirect Leadership: Transformational leadership at a distance. In B. M. Bass, \& B. J. Avolio (Eds.), Improving organizational effectiveness through transformational leadership (pp. 26-47). Thousand Oaks, CA: Sage Publications.

Yammarino, F. J., \& Jung, D. I. (1998). Asian Americans and leadership: A levels of analysis perspective. Journal of Applied Behavioral Science, 34(1), 47-57.

Yukl, G. (1998). Leadership in organizations (4th ed.). Englewood Cliffs, NJ: Prentice Hall.

Yukl, G. (1999). An evaluation of conceptual weaknesses in transformational and charismatic leadership theories. The Leadership Quarterly 10(2), 285-305.

Zaccaro, S. J. (2002). The nature of executive leadership. Washington, DC: American Psychological Association. 


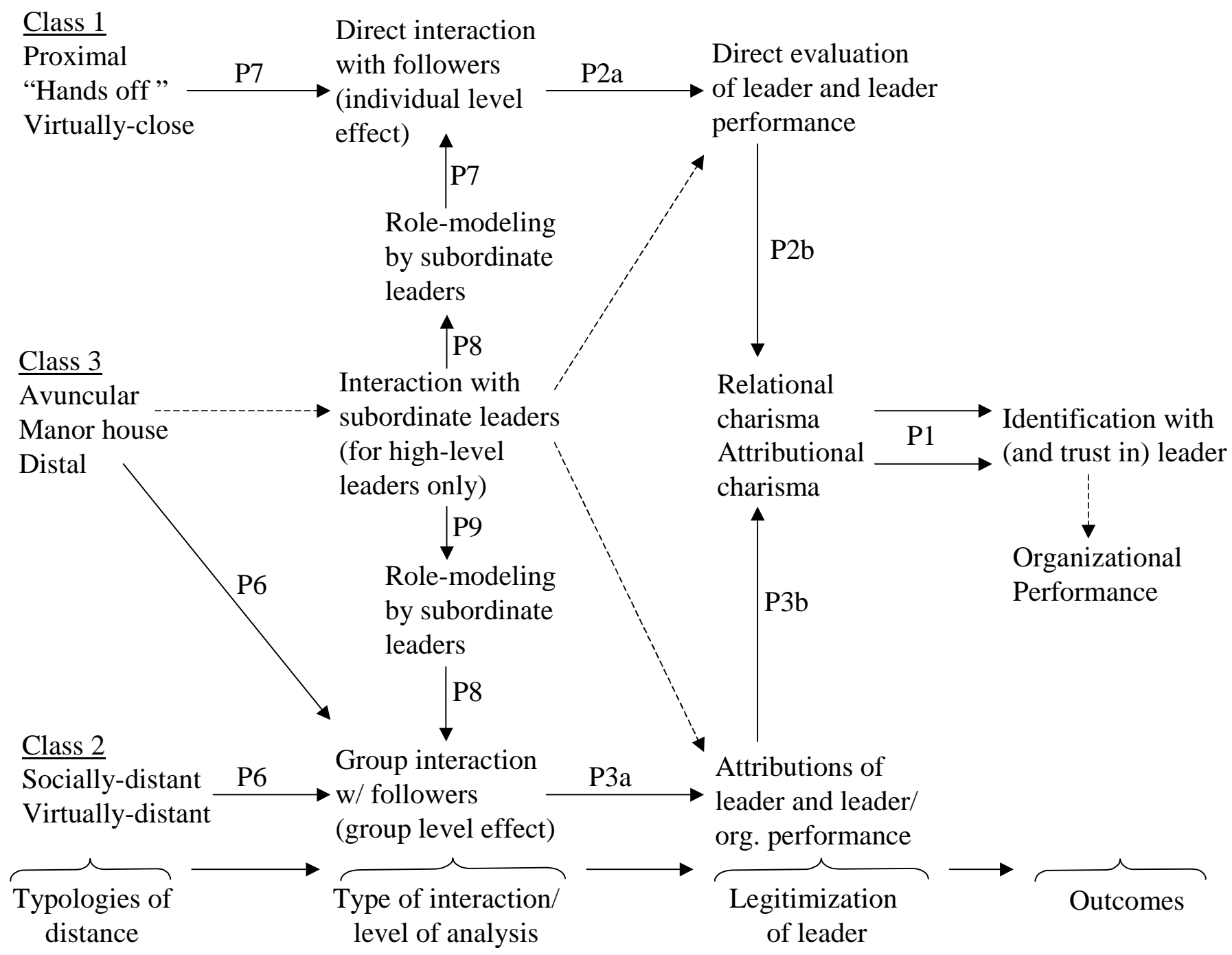

Figure 1: Leader distance model 